\title{
Relaxation of species-specific neighborhood effects in Bornean rain forest under climatic perturbation
}

\author{
David M. Newbery and Peter Stoll ${ }^{1}$ \\ Institute of Plant Sciences, University of Bern, Altenbergrain 21, CH-3013, Bern, Switzerland
}

\begin{abstract}
Evidence of negative conspecific density dependence (NDD) operating on seedling survival and sapling recruitment has accumulated recently. In contrast, evidence of NDD operating on growth of trees has been circumstantial at best. Whether or not local NDD at the level of individual trees leads to NDD at the level of the community is still an open question. Moreover, whether and how perturbations interfere with these processes have rarely been investigated. We applied neighborhood models to permanent plot data from a Bornean dipterocarp forest censused over two 10-11 year periods. Although the first period was only lightly perturbed, a moderately strong El Niño event causing severe drought occurred in the first half of the second period. Such events are an important component of the environmental stochasticity affecting the region. We show that local NDD on growth of small-to-mediumsized trees may indeed translate to NDD at the level of the community. This interpretation is based on increasingly negative effects of bigger conspecific neighbors on absolute growth rates of individual trees with increasing basal area across the 18 most abundant overstory species in the first period. However, this relationship was much weaker in the second period. We interpreted this relaxation of local and community-level NDD as a consequence of increased light levels at the forest floor due to temporary leaf and twig loss of large trees in response to the drought event. Mitigation of NDD under climatic perturbation acts to decrease species richness, especially in forest overstory and therefore has an important role in determining species relative abundances at the site.
\end{abstract}

Key words: conspecific competition; Danum Valley, Borneo; density dependence; Dipterocarpaceae; ENSO drought; neighborhood models; overstory species; rain forest tree community; randomization tests.

\section{INTRODUCTION}

In closed tropical forests, strong conspecific effects that limit juvenile tree growth in the neighborhood of adults can be interpreted as a form of abundance- or biomass-related dependence. This may lead to density dependence when growth translates to changes in tree population dynamics (Clark and Clark 1992, Zuidema et al. 2009). The expectation is that slower growing individuals will recruit less often, and be more likely to die, than faster growing ones. As a consequence of abundance dependence, juveniles would tend to grow better and be more likely to survive to adulthood when they are located farther away from, rather than close to, their current adults. Given that most species of tropical trees disperse to locations close to the adults (Condit et al. 2000), abundance dependence may put a check on the local density of conspecific trees and therefore give more opportunity for heterospecifics to grow and survive better within the neighborhood. The same reasoning applies to these heterospecific adults with regard to their own conspecific juveniles. Several authors have argued that this general process of tree-tree interactions might

Manuscript received 26 February 2013; revised 3 June 2013; accepted 5 June 2013. Corresponding Editor: T. P. Young.

${ }^{1}$ Corresponding author. E-mail: peter.stoll@ips.unibe.ch contribute to the maintenance of high species richness in tropical rain forests (Wright 2002), and more specifically to mixed lowland dipterocarp forests (Stoll and Newbery 2005). The central questions that remain are (1) how frequently do these conspecific interactions occur, (2) what are the mechanisms operating behind them, and (3) are they strong enough to have a controlling influence on tree community dynamics? Relevant data have been collected increasingly over the last two decades, from many sites world-wide, but as yet the appropriate hypothesis formulation and analytical approaches have been lacking. In this paper we present a way forward that argues for careful reconsideration of the role of conspecific and heterospecific interactions among trees.

Studies in tropical rain forest at Barro Colorado Island (BCI), Panama, have shown strong evidence of negative conspecific density dependence (NDD) operating on seedling survival (Harms et al. 2000, Comita and Hubbell 2009, Comita et al. 2010, Metz et al. 2010), and $1-\mathrm{cm}$ dbh (diameter at breast height) sapling recruitment (Wills et al. 1997), but for trees with dbh $\leq 4 \mathrm{~cm}$, NDD on recruitment was limited to just the very common species (Hubbell et al. 1990, Condit et al. 1994). Once above the $1-2 \mathrm{~cm}$ dbh sapling size, mortality appeared to be unaffected by neighborhood and seemed random (Wills and Condit 1999); conspecific effects on survival (all trees $\geq 1 \mathrm{~cm} \mathrm{dbh}$ ) were moderately strong in 13 of the 
124 most abundant species (Ahumada et al. 2004). The general postulate is that NDD at the seedling level is largely determined by various biotic (insect or pathogen) factors (Carson et al. 2008, Mangan et al. 2010, Terborgh 2012). Tests for NDD on small-tree growth have been very few though. For two understory species, Condit et al. (1994) showed small conspecific effects on growth of focal trees with $\mathrm{dbh} 1 \mathrm{~cm}$ to $<4 \mathrm{~cm}$ that were very close to adults. In a wider analysis of 60 species using the same size class and a nearest neighborhood modeling approach, Uriarte et al. (2004b) found only weak evidence of conspecific effects for six species: they suggested that once a tree at BCI moved from seedling to sapling or pole sizes, NDD was lost (Uriarte et al. 2005). Gilbert et al. (2001) showed a pathogen-specific small-tree effect for one particular species at BCI. Interestingly, we are not aware of any literature reporting main tests of NDD on growth of trees $\geq 4$ $\mathrm{cm} \mathrm{dbh}$ at BCI. In a forest in Puerto Rico strongly hurricane-disturbed, conspecific effects became very diffuse, suggesting that destabilization of tree neighborhoods changed competitive interactions while other recovery processes dominated (Uriarte et al. 2004a).

One hypothesis is that where NDD does happen, seedlings that survive grow into saplings and then small trees, largely freed now of their biotic constraints (i.e., pest and pathogens), and they then begin to interact competitively with the adults for common resources at a slightly larger spatial scale (Biging and Dobbertin 1992, Moravie et al. 1999, Vanclay 2006). Alternatively, where NDD mortality of seedlings does not happen close to adults, relatively more saplings would recruit to small trees, and in the same way come into competitive contact with the adults. Being, on average, closer to one another, they might interact more intensively than when seedlings had been previously thinned. In this way, NDD effects on small trees might either reinforce or substitute NDD at the seedling stage, albeit with a different mechanism now operating. A gradual shift from animal- or pathogen-mediated to tree competitive processes most likely occurs, with different balances between them for differing species at different sizes.

Given that the tests mentioned were almost all from one site (there are occasional scattered single-species examples from elsewhere, e.g., for seedlings $<1 \mathrm{~cm} \mathrm{dbh}$ only; Blundell and Peart [2004]), it is doubtful whether it can be generally concluded for tropical forests that NDD is operating among seedlings only, and not sometimes (or even frequently) just as strongly among the small-tree size class. At other sites, the situation might be reversed, or a mixture of NDD mechanisms operate. In the temperate relatively species-poor forests, there is more evidence for NDD operating on small trees as a result of competition from larger conspecific ones (Canham et al. 2004, 2006). In the tropical forests after thinning among the seedlings, and perhaps smaller saplings, conspecific trees are often not close enough to compete directly, unless they are strongly clustered as a result of limited dispersal (Condit et al. 2000, Seidler and Plotkin 2006) or edaphic factors selecting their local distributions (Ashton 1998, Bagchi et al. 2011). In some cases, positive density dependence (PDD) may be operating, whereby seedlings, saplings, and smaller trees are facilitated in their growth and clustering is thereby strengthened. We conjecture that NDD may switch to PDD during ontogeny.

Considering juveniles and adults as small and large trees, respectively, the primary mechanisms for NDD most likely involve one-sided competition for light (Kohyama 1992, Sorrensen-Cothern et al. 1993), and the secondary ones, presumably, involve two-sided competition for nutrients; although for the latter there have been no competition studies on fertile tropical soils. Even so, interactions between neighboring trees are not expected to be sustained at a constant and high level when perturbations occur, because these interferences lead to a relaxation of the adults' competitive effects and the juveniles experience a corresponding release from competition. If conspecific effects, in particular, are reduced, this would allow an increase in local dominance of those strongly self-competitive species as abundance dependence (and then as a consequence, density dependence) temporarily weakens. By comparing periods with and without a naturally occurring perturbation, change in strength of conspecific effect can be estimated, other factors (e.g., large successional shifts in tree species composition) remaining largely constant. This does not rule out coincident climatic change (e.g., Feeley et al. 2011) affecting sequential intervals differently, but this is probably small in a period of two decades (see Newbery et al. 2011).

We pursued this idea using data from a lowland dipterocarp rain forest at Danum (northeastern Borneo), where, in a first relatively unaffected period, our previous analyses had demonstrated strong conspecific effects among the dominant overstory species, and, in the second period following a major drought, perturbation was recorded. We suspected that the more abundant a species (in terms of biomass), the stronger would be its conspecific effects, if these were operating generally. Alternatively, such effects were likely to appear when the same species as the focus one dominated the neighborhood, and when strength of competition was simply size related, i.e., effects were then conspecific "by default."

The primary interest here is not to explain high diversity in tropical rain forests in the form, e.g., of a community compensation hypothesis (Connell et al. 1984, Webb and Peart 1999), but rather to explain the abundance of the dominant tree species. Newbery et al. (1992) calculated that the overstory Dipterocarpaceae at Danum (mainly species of Shorea, Parashorea, and Dipterocarpus) contributed as much as $49 \%$ and $66 \%$ of the plots' basal area in 1986 for trees $\geq 30$ and $\geq 100 \mathrm{~cm}$ gbh (girth at breast height), respectively (16\% and $43 \%$ of tree density). As a result of their large sizes and 
emergent canopy status, these species doubtless play a major role (through shading, and water and nutrient fluxing) in the dynamics of dipterocarp forests (Manokaran and Kochummen 1987, Ashton and Hall 1992). How their juveniles recruit from the understory in turn affects basal area development and succession of the stand (Newbery et al. 1999). In biomass terms, such large trees also utilize a disproportionately greater part of site resources than do smaller ones, so if neighbor conspecific effects do operate through competition, it is most likely to be due to these overstory species. Likewise, these large trees are the ones first and most aerially exposed to climatic variations affecting abovecanopy conditions during a drought (Walsh and Newbery 1999).

The perturbation came in the form of a moderately strong climatic event caused by the 1998 El Niño Southern Oscillation (ENSO). The forest at Danum was not disturbed, in the sense of significant damage to trees and biomass loss, but it was noticeably perturbed. Overstory mortality rates increased slightly, tree growth overall slowed, and leaf density in the upper canopy was temporarily and unevenly reduced as a result of abnormally high leaf and small-branch shedding rates (Newbery and Lingenfelder 2004, 2009). The ENSO had a much more pronounced effect, though, on the dynamics of the small trees in the understory, significantly affecting the stem growth rates of many species, both during and after the event. The strong water stress imposed by several weeks of little or no rainfall (see Newbery and Lingenfelder 2009) first suppressed growth; then, in a recovery phase in which light levels in the understory were necessarily raised due to changes in overstory cover, growth rates recovered or even overcompensated (Newbery et al. 2011). Different tree species responded in widely different ways to the perturbation, leading to a complex mix of species' dynamics and their population trajectories. The small trees $(10$ to $<50 \mathrm{~cm}$ gbh) of the understory consist of both true understory species and juveniles of overstory species in the proportions of about 0.85:0.15. Based on past records, the frequency expectation of a moderately strong to strong perturbation is once in $\sim 15$ years (Walsh 1996): since 1998, there has been just one weak event in 2010.

With regard to conspecific effects of large trees, our null hypothesis was that the perturbation would affect species similarly and would release the growth of juveniles of overstory species in proportion to their abundance as large trees, the strongly dependent ones being those most benefiting. Juveniles that survived would soon be subject to renewed competitive pressure once the forest had recovered, given that few large trees actually died and gap formation rates did not significantly increase (Newbery and Lingenfelder 2004). If no deaths resulted, the perturbation would then have no net long-term effect on species composition and relative abundances; the perturbation had simply placed a temporary stay on abundance dependence. The alternative hypothesis was that species might differ individually in response to the perturbation itself, and in their linked conspecific effects, with some experiencing release and others not, depending on their specific physiologies and phenologies. In this latter case, shifts in species composition and abundances over time would be expected. Our third question may therefore be reformulated more precisely to ask whether perturbations advance high abundances of some species, and hence decrease species richness in a tree community, or whether they limit them and accordingly increase that richness.

\section{Material and Methods}

\section{Study site}

Two permanent 4-ha plots $(100 \times 400 \mathrm{~m})$ were established in the Danum Valley Conservation Area (Sabah, Malaysia) and were first enumerated in 1986 (Newbery et al. 1992, 1999). They are located $\sim 65 \mathrm{~km}$ inland of the east Bornean coast, at $4^{\circ} 57^{\prime} 48^{\prime \prime} \mathrm{N}$ and $117^{\circ} 48^{\prime} 10^{\prime \prime} \mathrm{E}$, and $\sim 220 \mathrm{~m}$ above sea level. The plots are positioned $\sim 280 \mathrm{~m}$ apart, and each encompasses a lower slope-to-ridge gradient typical of the local topography: the soils at Danum are relatively nutrient rich for the region (Newbery et al. 1996). Rainfall at the site is generally quite even over the year and totals $\sim 2800 \mathrm{~mm}$, on average (Walsh and Newbery 1999). The forest is primary and dominated by dipterocarp species of the Parashorea malaanonan type (Fox 1972). All trees $\geq 10$ $\mathrm{cm}$ girth at breast height (gbh) were mapped, measured for gbh, and identified; $99.4 \%$ of enumerated individuals were identified to species. Vouchers are stored at the Sandakan (Sabah) and Leiden (Netherlands) Herbaria. Complete re-enumerations were made in 1996, 2001, and 2007. For the present paper, we primarily analyzed data of the two longer periods, 1986-1996 ( $\mathrm{P}_{1}, 10.0$ years $)$ and 1996-2007 ( $\mathrm{P}_{2}, 11.1$ years $)$. At the start, the two plots contained $\sim 18000$ trees; by 2007 , the total number, including recruits, reached $\sim 23500$. For further details of the measurement techniques, refer to Lingenfelder and Newbery (2009).

\section{Species selection}

Preliminary analyses of absolute stem growth rate in basal area (agr, in $\mathrm{cm}^{2} / \mathrm{yr}$ ) vs. basal area $\left(\mathrm{ba}\right.$, in $\mathrm{cm}^{2}$ ) per tree (both $\ln$-transformed) for the two periods $\mathrm{P}_{1}$ and $\mathrm{P}_{2}$ revealed a general relationship close to linear for trees with $\mathrm{gbh} \leq 100 \mathrm{~cm}$. This growth rate was found as $\left(\mathrm{ba}_{t_{2}}\right.$ $\left.-\mathrm{ba}_{t_{1}}\right) / t$, where $t_{1}$ and $t_{2}$ were the start and end of a given period of length $t$ years. To allow for $\ln$-transformation of small negative values, a constant $\left(1 \mathrm{~cm}^{2}\right)$ was added to each agr value. Small-to-medium-sized individuals $(10 \geq$ $\mathrm{gbh} \leq 100 \mathrm{~cm}$ ) were considered as possible focus trees, the trees involved being necessarily those surviving to the ends of periods. A further restriction imposed was that focus trees were located $\leq 20 \mathrm{~m}$ from plot edges, to allow for full evaluation of their neighborhoods up to a radius 
equal to that distance. Individuals with residuals more negative than $-3 \mathrm{SD}$ were iteratively excluded from the agr vs. ba relationship. An over-understory index (OUI) was already available for the 100 most abundant species in the plots (see Newbery et al. 2011). The OUI is a continuous scale of $0-100$ on which 0 and 100 , respectively, indicate that of the trees with gbh $\geq 10$ $\mathrm{cm}$, none or all had $\mathrm{gbh} \geq 30 \mathrm{~cm}$. Based on stem diameter frequency distributions, OUI shows the degree to which a species is found more in the understory or overstory of the forest at Danum. Screening of the plot data yielded 37 species with $n>50$ potential focus trees in $\mathrm{P}_{1}$, seven of which were overstory (OUI $\left.>55\right), 15$ intermediate (OUI 20-50), and 15 understory (OUI $<$ 20); see Appendix A: Table A1. Total plot basal area (i.e., BA of all species) at $t_{1}$ was $30.7 \mathrm{~m}^{2} /$ ha for $\mathrm{P}_{1}$ and $33.3 \mathrm{~m}^{2} /$ ha for $\mathrm{P}_{2}$. The contributions made by the 37 species were $15.4 \mathrm{~m}^{2} / \mathrm{ha}(50.2 \%)$ and $16.5 \mathrm{~m}^{2} / \mathrm{ha}(49.5 \%)$, respectively; corresponding contributions of only the overstory species were $8.2 \mathrm{~m}^{2} /$ ha $(26.7 \%)$ and $9.4 \mathrm{~m}^{2} /$ ha $(28.2 \%)$.

\section{Tree neighborhood effects}

The agr of focus trees between the two times, $t_{1}$ and $t_{2}$, was modeled statistically as a function of size at the start of the period $\left(\mathrm{ba}_{t_{1}}\right)$. Two neighbor terms that were sums of the ba of trees that survived the period and were larger than the focus tree at $t_{1}$ were modeled as either heterospecifics (HET) or conspecifics (CON) (following the results of Stoll and Newbery 2005). All variables were $\ln$-transformed to normalize their errors. The neighborhood model was: $\ln \left(\operatorname{agr}_{t_{1}-t_{2}}\right)=$ intercept $+\alpha$ $\ln \left(\mathrm{ba}_{t_{1}}\right)+\beta \ln \Sigma\left(\mathrm{ba}_{\mathrm{HET}}\right)+\gamma \ln \Sigma\left(\mathrm{ba}_{\mathrm{CON}}\right)+$ error, with intercept, $\alpha, \beta$, and $\gamma$ as the regression parameters to be estimated by the least-squares approach. The summations $\mathrm{ba}_{\mathrm{HET}}$ and $\mathrm{ba}_{\mathrm{CON}}$ were evaluated in 1-m steps for all neighborhood radii between 1 and $20 \mathrm{~m}$, when the border was $20 \mathrm{~m}$ (or to 10 and $15 \mathrm{~m}$ when the border was set to less). As for agr, $1 \mathrm{~cm}^{2}$ was added to each $\Sigma$ (ba) neighborhood value to deal with ln-transformation of zero values. Models for all possible combinations of radii for HET and $\mathrm{CON}$ neighbors were evaluated (i.e., 400 cases), and the best-fitting combination, judged by the highest adjusted $R^{2}$ value, was found for each species and period (for further details, see Stoll and Newbery 2005). Small best-fitting radii that led to fewer than five trees without HET, or fewer than five trees with CON, neighbors were discarded to reduce spurious results. Fitting of $\mathrm{ba}_{t_{1}}$ and $\mathrm{ba}_{\mathrm{HET}}$ terms was mainly to account for variance due to initial size and the basal area contribution of all other non-conspecific species in the neighborhoods, and thereby increase the power of the regression model to detect $\mathrm{CON}$ effects. Fitting $\mathrm{ba}_{t_{1}}$ as a term was also equivalent to transforming $\ln (\mathrm{agr})$ to relative growth rate (rgr). Model-fitting procedures were made using R (R Development Core Team 2012).

CON effect size was calculated as the squared partial correlation coefficient, $r^{2}=t^{2} /\left[t^{2}+(n-4)\right]$, using the $t$ value associated with the regression coefficient of the CON term, and where $n-4$ is the residual degrees of freedom for the model $\left(t=r \sqrt{ }(n-4) / \sqrt{ }\left(1-R^{2}\right)\right.$; (Cohen 1988, Warner 2012); $R^{2}$ was derived for the overall fit. HET effect size, and that for $b_{t_{1}}$, were found in a similar way. The partial correlation coefficient is a standardized form of the regression coefficient, $r_{\mathrm{CON}}=$ $\gamma \mathrm{SD}_{\ln \left(\mathrm{ba}_{\mathrm{CON}}\right)} / \mathrm{SD}_{\ln (\mathrm{agr})}$. CON effect can be read as the proportion of the variance in $\ln (\mathrm{agr})$ accounted for by $\ln \left(\mathrm{ba}_{\mathrm{CON}}\right)$ when the other independent variables (i.e., $\ln \left(\mathrm{ba}_{t_{1}}\right)$ and $\left.\ln \left(\mathrm{ba}_{\mathrm{HET}}\right)\right)$ are adjusted to be at their mean values. To find the absolute difference in agr for one unit change in $\Sigma\left(\mathrm{ba}_{\mathrm{CON}}\right)$, on its transformed logarithmic scale and per species in $P_{1}$, values for mean $\ln \left(b_{t_{1}}\right)$ and $\ln \Sigma\left(\mathrm{ba}_{\mathrm{HET}}\right)$ were first put in the fitted regression equation, and then the back-transformed values of $\ln (\mathrm{agr})$ were found when either mean $\ln \Sigma\left(\mathrm{ba}_{\mathrm{CON}}\right)$ or mean $\ln \Sigma\left(\mathrm{ba}_{\mathrm{CON}}\right)-1$ were inserted. The difference between these last two estimates divided by the first gave the relative change in agr per unit $\ln \Sigma\left(\mathrm{ba}_{\mathrm{CON}}\right), \operatorname{ragr}_{\mathrm{CON}}$. The procedure was repeated for each species in $\mathrm{P}_{2}$ using the corresponding regression equations, except that here values of mean $\ln \left(\mathrm{ba}_{t_{1}}\right)$ were those of $\mathrm{P}_{1}$, in order that any calculated differences in agr due to $\mathrm{CON}$ neighborhood would be unaffected by a changes in mean agr between $\mathrm{P}_{1}$ and $\mathrm{P}_{2}$.

To test whether CON effects were really speciesspecific and not a consequence of being locally predominant in neighborhoods per se, the neighborhood analyses were repeated with two separate sets of $n^{\prime}=100$ simulations. In the first, all trees within the plots were repositioned, using a partially restricted randomization procedure; in the second, the taxonomic identity of neighbors was reassigned at random, based upon the relative frequency distributions of species, within each of 28 size classes, across the plots. Full details of the computations are given in Appendix B. Both approaches are forms of null models. In the former, individuals of species, retaining their sizes, are moved about (often outside of neighborhoods) and any spatial clustering within species is obviated. In the latter, positions and sizes remain unchanged, but a tree receives another (or, occasionally, the same) name. Neighborhood models were also fitted (without sensitivity analysis) for the two sub-periods $\mathrm{P}_{2 \mathrm{a}}(1996-2001)$ and $\mathrm{P}_{2 \mathrm{~b}}(2001-2007)$. The aim was to test whether CON effects differed between the sub-period around the ENSO event and the one directly following it. We expected that the strong CON effects seen in $\mathrm{P}_{1}$ would start to return in that second half of $\mathrm{P}_{2}$.

\section{Species dependence on abundance}

A simple linear model, which included the species' plot-level basal area (BA, ln-transformed), OUI, and their interaction, was fitted to the originally selected 37 species, for each period separately. To visualize the fitted model, lines were derived for the mean indices of the understory, intermediate, and overstory (using OUI = 
$10,37.5$, and 77.5 for the 100 species; Newbery et al. 2011); for the 37 species, mean OUI was very close at $11.0,37.9$, and 69.8, respectively. For an expanded set of 18 overstory species (the original seven plus 11 less frequent ones with $n \geq 20$ focus trees but $<50$ focus trees; Appendix A: Table A1), a simpler model, which fitted CON effect size only to BA, sufficed.

Dependence on abundance was tested for the 100 simulations of the two null-model sets, finding CON effects from each species' regressions. Radii of bestfitting models were found independently for each run that led to highly conservative testing. Regressions of CON effects on BA were calculated for each randomization set, and the minima and maxima of all graphed lines defined their $99 \%$ confidence envelopes. The hypothesis here was that if the empirical slope (and secondarily the intercept) were outside these limits, the CON effect could be interpreted as being real, in the sense of being species-specific and not an artifact of a species' locally high relative abundance. The first set of randomizations follow the spatial null-hypothesis approach. For the second set, however, the null hypothesis is more subtle. Conspecifics (of the 18 species studied) contributed much of the forest basal area, in the largest size classes, especially, as they were the most abundant overstory species in the plots; thus the reallocation of names could not be completely free of a default CON identity because large trees were quite often given (at random) the same name again. The possibility of misinterpreting the effect as true, and not an artifact, was assessed by estimating either the probability of any tree of a species within a size class being identically renamed, or the probability (for each species) that an individual, within its neighborhood, would receive the same name again. Computational details are given in Appendix B: Tables B1 and B2.

Three types of sensitivity analysis (Appendix C) were also performed to evaluate the potential effects of (1) excluding focus trees with negative or zero values of agr, (2) increasing the area within the plots that was sampled, and hence focus-tree sample sizes (by reducing border width to 10 or $15 \mathrm{~m}$ ), and (3) allowing for linear distance decay of neighborhood terms (i.e., ba of an individual neighbor, within a specified radius, was divided by its distance to the focus tree). Additionally, we evaluated effects of including or excluding dead trees as neighbors (Appendix D: Table D1) and effects of possible gbh measurement errors on large trees (Table D2).

Finally, to interpret CON effects in the context of plot dynamics and make a link to density dependence as a population process (following Newbery and Lingenfelder 2009), annualized mortality $\left(m_{\mathrm{a}}\right)$, recruitment $\left(r_{\mathrm{a}}\right)$, and relative stem growth ( $\mathrm{rgr})$ rates were drawn on for all those individuals of the 18 overstory species in the size class $\left(10\right.$ to $<100 \mathrm{~cm} \mathrm{gbh}$ ) for the whole-plot areas in $\mathrm{P}_{1}$ and $\mathrm{P}_{2}$ (D. M. Newbery and C. E. Risdale, unpublished data).

\section{Results \\ Changing CON effect with time}

Most of the overstory species showed significantly strong negative effects of larger conspecific neighbors $(\mathrm{CON})$ on absolute stem growth rates (agr) of focus trees in $\mathrm{P}_{1}$, and indeed Shorea johorensis, S. pilosa, and S. parvifolia, with very high plot-level basal areas (BA), had the strongest decreases in growth (Fig. 1a). The pattern of the overstory was markedly different from that of the understory and intermediate story, whose CON effects were generally much weaker and showed much less dependence on plot-level BA. Nevertheless, some non-overstory species among the 37 that also attained high BA values, e.g., Shorea fallax (intermediate) and Mallotus wrayi (understory), showed less strong, but significant, negative CON effects. By contrast, negative CON effects on agr in $\mathrm{P}_{2}$ were weaker than in $\mathrm{P}_{1}$ for many species, more species showing also slight positive effects (Fig. 1b); and the strong negative relationship with $\mathrm{BA}$ in the overstory of $\mathrm{P}_{1}$ was lost in $\mathrm{P}_{2}$. Different high-BA overstory species reacted very differently to the change from $\mathrm{P}_{1}$ to $\mathrm{P}_{2}$ : Shorea pilosa and $S$. parvifolia kept the strong negative effects of $\mathrm{P}_{1}$ in $\mathrm{P}_{2}$, whereas $S$. johorensis and Parashorea malaanonan lost them (Fig. 1). BA, OUI, and their interaction explained $64 \%$ of the variation in CON effect in $\mathrm{P}_{1}$, with the coefficients for OUI and $\mathrm{BA} \times$ OUI both being significantly negative (Table 1 ). In $\mathrm{P}_{2}$, the model fit was much poorer, with only OUI being just marginally significant and the BA $\times$ OUI interaction far from significant (Table 1).

Based on the strong contribution made by overstory species to the relationship between CON effects on agr and BA (Fig. 1), the set of seven species was expanded to 18, as explained in the Methods. The coefficients for the regression model fits for each of these species, with their effect sizes, are given in Appendix E: Tables E1 and E2. The relationship for these 18 species was highly significant in $\mathrm{P}_{1}$, but not significant in $\mathrm{P}_{2}$ (Fig. 2, Table 2). When the full neighborhood analysis was repeated to include also the ba of neighbors at $t_{1}$ that died within periods (these being alive for some unknown portion of a period), the results of the $\mathrm{CON}$ effects on agr and $\mathrm{BA}$ relationship for the 18 species barely changed (Appendix D: Table D1). Correcting for a small number $(n=19)$ of large-tree gbh values that were seemingly underestimated in 1986 led to almost identical results (Appendix D: Table D2). Fitting neighborhood models for the subperiods of $\mathrm{P}_{2}$ showed no significant dependence of CON effects on plot-level BA (Appendix F: Table F1, Fig. F1). The results were therefore very similar overall to those of $\mathrm{P}_{2}$.

In $\mathrm{P}_{1}$, none of the sets with randomized tree positions or randomized identities showed intercepts or slopes as negative as the observed ones (Appendix B: Fig. B1a): the intercept (at $\mathrm{BA}=1)$ and slope of the empirical data for BA $>0.4$ were both well below the lower edge of the 

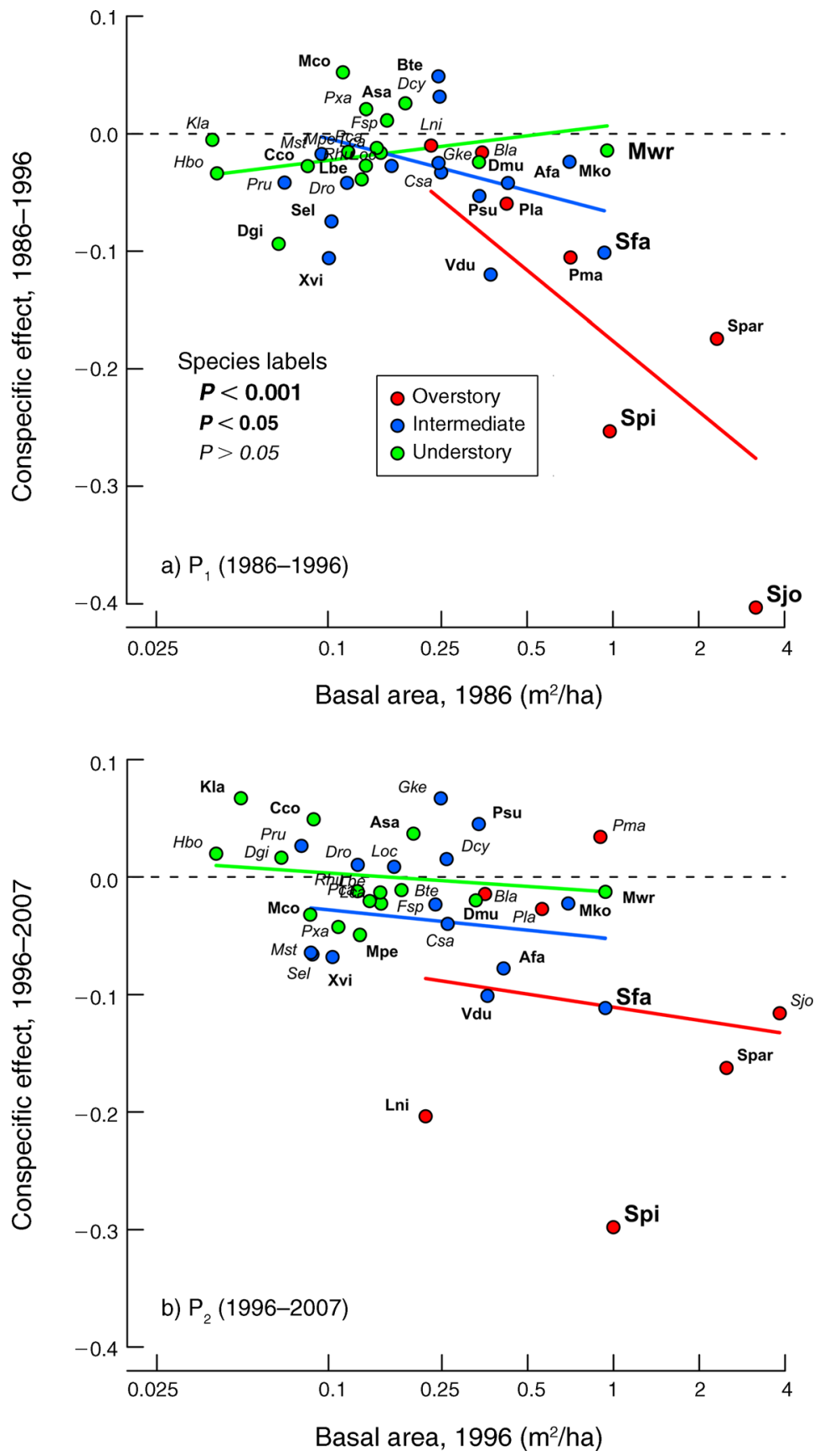

FIG. 1. Relationship between effect size of larger conspecific neighbors (CON) on absolute stem growth rate (agr) in neighborhood models and plot basal area (BA) of 37 tree species with $>50$ focus trees at Danum, Borneo (see Appendix A: Table A1 for full names of species) for (a) period $1\left(\mathrm{P}_{1}, 1986-1996\right)$ and (b) period $2\left(\mathrm{P}_{2}, 1996-2007\right)$. The fitted model is shown by lines for trees classified as undersory, intermediate, and overstory species (colored circles); note the log scale for basal area. Significance of the CON effect is indicated by the size and boldness of the abbreviation font. See Table 1 for statistics.

confidence envelope (Fig. 2a). For $\mathrm{P}_{2}$, there was some overlap in intercepts and slopes (Appendix B: Fig. B1b), and the line for the empirical data lay within the two confidence bands (Fig. 2b). The trends in $\mathrm{P}_{2}$ were similar in outcome to the randomizations of $\mathrm{P}_{1}$. Therefore, when locations of conspecifics were moved within the plots (often away and outside of the focus trees' neighborhoods), or trees as neighbors were no longer labeled as conspecifics per se (apart from some chance same-name replacements under randomization; see Appendix B), then the CON effects on agr in relation to BA were apparently weakened, and much more so in 
TABLE 1. Regression models for effects of larger conspecific neighbors (CON) on absolute stem growth rate (agr) in two periods $\left(\mathrm{P}_{1}, 1986-1996 ; \mathrm{P}_{2}, 1996-2007\right)$ using 37 tree species with $>50$ focus trees at Danum, Borneo.

\begin{tabular}{|c|c|c|c|c|c|c|c|c|}
\hline \multirow{2}{*}{$\begin{array}{c}\text { Intercept } \\
\text { and variable }\end{array}$} & \multicolumn{4}{|c|}{$\mathrm{P}_{1}:$ adjusted $R^{2}=64.0 \%$} & \multicolumn{4}{|c|}{$\overline{\mathrm{P}_{2}: \text { adjusted } R^{2}=23.9 \%}$} \\
\hline & Estimate & SE & $t_{33}$ & $P$ & Estimate & SE & $t_{33}$ & $P$ \\
\hline Intercept & 0.035 & 0.037 & 0.9 & 0.36 & 0.002 & 0.049 & 0.0 & 0.98 \\
\hline BA & 0.064 & 0.038 & 1.7 & 0.096 & -0.013 & 0.049 & -0.3 & 0.79 \\
\hline OUI & -0.0027 & 0.0006 & -4.6 & 0.0001 & -0.0014 & 0.0008 & -1.9 & 0.07 \\
\hline $\mathrm{BA} \times$ OUI & -0.0034 & 0.0007 & -4.8 & $<0.0001$ & -0.0003 & 0.0009 & -0.3 & 0.73 \\
\hline
\end{tabular}

Note: CON effect size was the dependent variable, and plot basal area (BA), the over-understory index (OUI), and their interaction $(\mathrm{BA} \times \mathrm{OUI})$ were the independent variables.

$\mathrm{P}_{1}$ than in $\mathrm{P}_{2}$. This suggests a relaxation of true $\mathrm{CON}$ effect on agr between periods, particularly for several of the overstory species with the highest plot BA. The parameters, and their significance levels, for the relationships between CON effects on agr and BA changed very little when subject to the three types of sensitivity analysis, either for the 37 species (Appendix C: Table $\mathrm{C} 1$ ), or the 18 overstory ones (Table C2). This indicated a high level of robustness for the results.

The probability that upon randomization a tree, anywhere in the plots, will have the same name (be it the same or a different-sized tree within the class limits) could rise to $35 \%$, and was typically around $5-20 \%$, for dipterocarp trees $>150 \mathrm{~cm}$ gbh (tested for $\mathrm{P}_{1}$ only; Appendix B: Table B1). On an individual-tree basis within the sampled neighborhoods (i.e., the tree was also at same distance as before from the focus tree), the maximum was $\sim 6 \%$, and typically $1-4 \%$ (Table B2). Therefore, a CON effect cannot be completely nullified by any randomization procedure, and this analysis provides an explanation as to why, at high BA, the confidence bands are shifted slightly above those for randomization of locations. It would also account for the small negative slope for CON effect on agr vs. $\ln (\mathrm{BA})$ showing in $\mathrm{P}_{2}$, even if there were no true $\mathrm{CON}$ effects operating in that period.

\section{CON effects in relation to plot dynamics}

Between $\mathrm{P}_{1}$ and $\mathrm{P}_{2}$, the composition of the potential focal samples (border $20 \mathrm{~m}$ ) of each species changed because some trees alive throughout $\mathrm{P}_{1}$ had died by the end of $\mathrm{P}_{2}$ (or advanced in gbh out of the focus-tree size class between $\mathrm{P}_{1}$ and $\mathrm{P}_{2}$ ) and were not used in that period, and others that recruited at the start of, and were alive throughout, $\mathrm{P}_{2}$ were not used in $\mathrm{P}_{1}$. Change in CON effect on agr for the 18 overstory species was not significantly correlated, however, with proportions of the number of trees "outgoing" from, and "incoming" to, the size class of the focus trees respectively sampled in $\mathrm{P}_{1}$ and $\mathrm{P}_{2}(r=0.21, P=0.41 ; r=0.21, P=0.40 ; \mathrm{df}=$ $16)$, nor when these were combined as proportion "outgoing or incoming" $(r=0.26, P=0.30)$, suggesting that change of individuals as focus trees was not in itself an explanation for the loss of CON effects in $\mathrm{P}_{2}$. Partialling out the effect of $\ln (\mathrm{BA})$ reduced the correlations, especially for outgoers $(r=0.02,0.18$, and 0.13 ; correspondingly, $P=0.95,0.48,0.62$ ), again indicating an indirect effect of mortality in $\mathrm{P}_{1}$. CON effect in $\mathrm{P}_{1}$ alone was better correlated with proportion outgoing from $\mathrm{P}_{1}(r=-0.44, P=0.07)$; CON effect in $\mathrm{P}_{2}$ was less well correlated with proportion incoming to $\mathrm{P}_{2}$ $(r=-0.26, P=0.30)$. Loss of CON effect was therefore not significantly related to sample composition.

Using dynamics variables found for the 18 overstory species at the whole-plot level (trees 10 to $<100 \mathrm{~cm}$ gbh), the negative correlation between $\mathrm{CON}$ effect and $\ln (\mathrm{BA})$ in $\mathrm{P}_{1}(r=-0.78, \mathrm{df}=16, P<0.001$; Fig. 2a) was little reduced when effects of either $r_{\mathrm{a}}$ or rgr were partialled out, i.e., adjusted to their means $(r=-0.75$ and -0.73 , respectively; $\mathrm{df}=15, P<0.001)$. However, it was reduced much more when $m_{\mathrm{a}}$ was partialled out $(r=$ 0.59 , df $=15, P=0.013$ ), due to $m_{\mathrm{a}}$ being strongly correlated with both $\ln (\mathrm{BA})$ and CON effect $(r=0.75$, df $=16, P<0.001 ; r=-0.64, \mathrm{df}=16, P=0.004)$. In $\mathrm{P}_{2}$, the weaker negative correlation between $\mathrm{CON}$ effect and $\ln (\mathrm{BA})(r=-0.36, \mathrm{df}=16, P=0.14$; Fig. $2 \mathrm{~b})$ was much less affected by the partialling out of $m_{\mathrm{a}}, r_{\mathrm{a}}$, or $\operatorname{rgr}(r=$ $-0.18,-0.24$, and -0.25 , respectively; $\mathrm{df}=15 ; P=0.48$, $0.36,0.34)$. These results point to a structural link between CON effect on agr as abundance dependence and $\ln (\mathrm{BA})$ on $m_{\mathrm{a}}$ as density dependence.

\section{CON effects in relation to agr change with time}

CON effect across the 18 species was $-0.058 \pm 0.038$ (mean $\pm \mathrm{SE}$; range -0.40 to 0.28 ) in $\mathrm{P}_{1}$ and $-0.050 \pm$ 0.030 ( -0.30 to 0.23 ) in $\mathrm{P}_{2}$ (see Fig. 2b); the corresponding mean values for $\operatorname{ragr}_{\mathrm{CON}}$ were similar at $-0.086 \pm$ 0.039 (range -0.43 to 0.19$)$ and $-0.042 \pm 0.032$ ( -0.29 to 0.19 ) (Table 3). The two variables were strongly correlated $\left(\mathrm{P}_{1}, r=0.95 ; \mathrm{P}_{2}, r=0.90 ; \mathrm{df}=16, P<\right.$ 0.001 ) and their major-axis (model-2) regression slopes were close to unity $\left(\mathrm{P}_{1}, 1.03 \pm 0.08 ; \mathrm{P}_{2}, 1.06 \pm 0.14\right)$. This means that the CON effect, for these data from Danum, is a very close representation of the absolute rate of change in agr with ln-unit increase in conspecific BA change, implying also that variances of $\ln (\mathrm{agr})$ and $\ln \left(\mathrm{BA}_{\mathrm{CON}}\right)$ were not so dissimilar in either period. The mean difference between $\mathrm{CON}$ effects, $\mathrm{P}_{2}-\mathrm{P}_{1}$, was also very close to zero $(0.008 \pm 0.035$, range -0.299 to 0.287 ; see Table 3).

Between periods, however, the back-transformed agrestimates at mean $\ln \Sigma\left(\mathrm{ba}_{\mathrm{CON}}\right)$ in $\mathrm{P}_{1}$ and $\mathrm{P}_{2}$ had a 

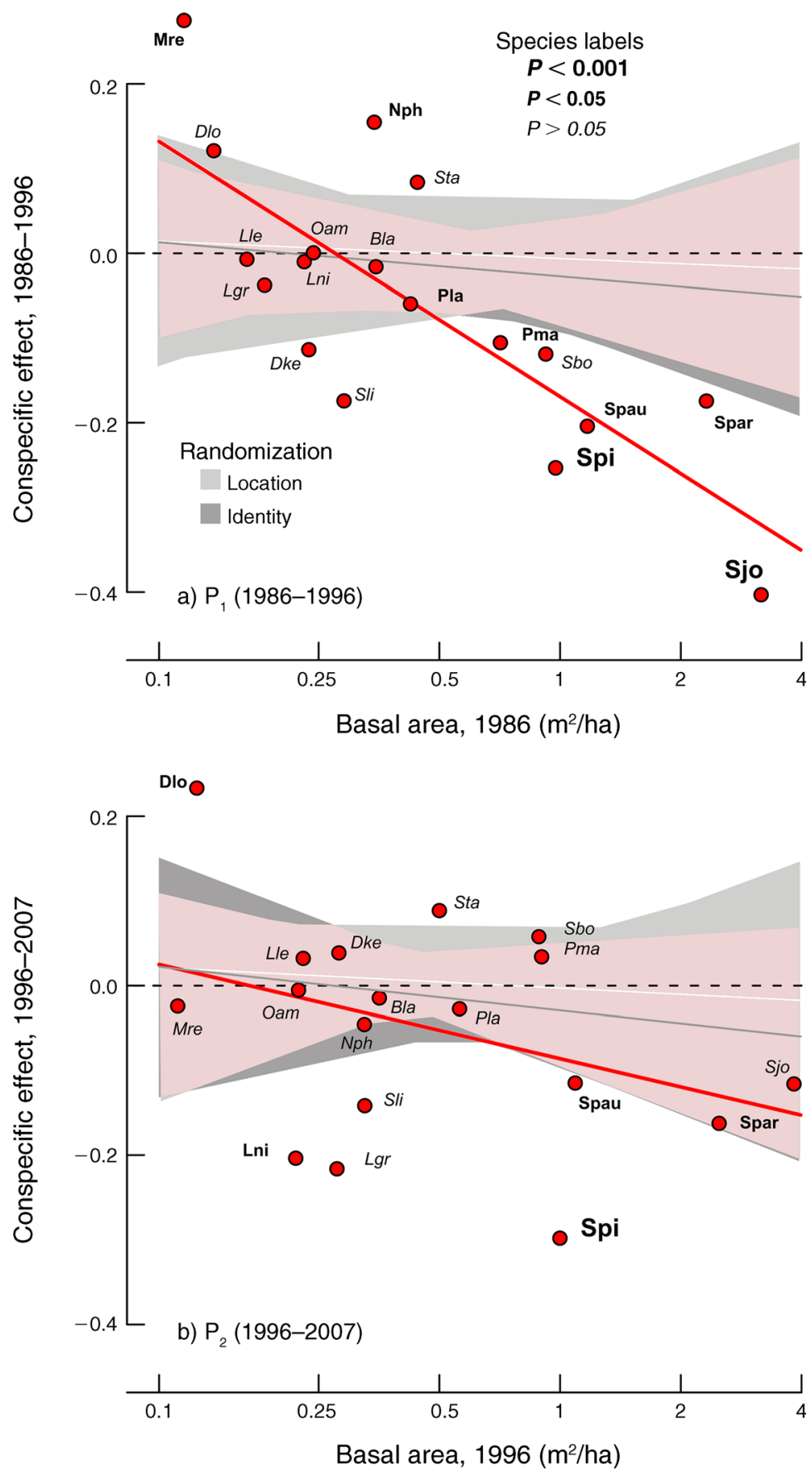

FIG. 2. Relationship between effect sizes of larger conspecific neighbors (CON) on absolute stem growth rate (agr) in neighborhood models and plot basal area (BA, log scale) of 18 overstory tree species with $>20$ focus trees at Danum for (a) period 1 $\left(\mathrm{P}_{1}, 1986-1996\right)$ and $(\mathrm{b})$ period $2\left(\mathrm{P}_{2}, 1996-2007\right)$. Regression lines (red; see Table 2 for statistics) are shown together with $99 \%$ confidence envelopes (shaded) and means (gray lines) from 100 runs with randomized locations (light gray) or identities (dark gray) and their overlap (pink). Note that none of the regression lines from the randomizations was outside the shaded areas. See Appendix A: Table A1 for full names of species.

relative change, $\operatorname{ragr}_{\mathrm{PER}}\left(=\left[\operatorname{agr}_{\mathrm{P}_{2}}-\operatorname{agr}_{\mathrm{P}_{1}}\right] / \operatorname{agr}_{\mathrm{P}_{2}}\right)$, on average of $0.09 \pm 0.10$ (range -0.62 to 1.12 ); the corresponding estimate using mean $\ln \Sigma\left(\mathrm{ba}_{\mathrm{CON}}\right)-1$ was $0.08 \pm 0.13$ ( -0.59 to 1.71 ), i.e., similar changes (nearly $10 \%$ increases) across periods, but much more variable differences between species (from $\sim 50 \%$ decrease to twofold increases), compared with $\operatorname{ragr}_{\mathrm{CON}}$ within $\mathrm{P}_{1}$ (Table 3).

Although at mean $\ln \Sigma\left(\mathrm{ba}_{\mathrm{CON}}\right), \operatorname{ragr}_{\mathrm{CON}}$ and $\operatorname{ragr}_{\mathrm{PER}}$ were positively, but not significantly, correlated $(r=$ 
TABLE 2. Regression models for effects of larger conspecific neighbors (CON) on absolute stem growth rate (agr) in two periods $\left(\mathrm{P}_{1}, 1986-1996 ; \mathrm{P}_{2}, 1996-2007\right)$ using 18 overstory species at Danum, Borneo.

\begin{tabular}{|c|c|c|c|c|c|c|c|c|}
\hline \multirow{2}{*}{$\begin{array}{c}\text { Intercept } \\
\text { and variable }\end{array}$} & \multicolumn{4}{|c|}{$\mathrm{P}_{1}:$ adjusted $R^{2}=58.1 \%$} & \multicolumn{4}{|c|}{$\mathrm{P}_{2}:$ adjusted $R^{2}=7.6 \%$} \\
\hline & Estimate & $\mathrm{SE}$ & $t_{16}$ & $P$ & Estimate & $\mathrm{SE}$ & $t_{16}$ & $P$ \\
\hline Intercept & -0.17 & 0.03 & -5.1 & $<0.0001$ & -0.09 & 0.04 & -2.3 & 0.036 \\
\hline $\mathrm{BA}$ & -0.30 & 0.07 & -5.0 & $<0.0001$ & -0.11 & 0.07 & -1.6 & 0.14 \\
\hline
\end{tabular}

Note: CON effect size was the dependent variable and plot basal area (BA) the independent variable.

$0.34, P=0.17)$, at mean $\ln \Sigma\left(\right.$ ba $\left._{\mathrm{CON}}\right)-1$ the correlation was significant $(r=0.53, P=0.026)$. Thus, as mean $\ln \Sigma\left(\right.$ ba $\left._{\mathrm{CON}}\right)$ lessened (by -1 unit), ragr $_{\mathrm{PER}}$ became more similar to $\operatorname{ragr}_{\mathrm{CON}}(\sim \mathrm{CON}$ effect $)$, i.e., the difference between periods was becoming less. A very similar result emerged when difference in $\mathrm{CON}$ effect, $\mathrm{P}_{2}-\mathrm{P}_{1}$, was correlated with the two $\operatorname{ragr}_{\mathrm{PER}}$ estimates: at mean $\ln \Sigma\left(\right.$ ba $\left._{\mathrm{CON}}\right)$, the correlation was not significant $(r=$ $-0.22, P=0.39)$; at mean $\ln \Sigma\left(\mathrm{baa}_{\mathrm{CON}}\right)-1$, it was significant $(r=-0.52, P=0.026)$.

\section{DisCUSSION}

Interplay of negative and positive effects on absolute growth rate (agr)

$\mathrm{CON}$ effects were significantly reduced in period 2 $\left(\mathrm{P}_{2}\right)$ compared with period $1\left(\mathrm{P}_{1}\right)$ by one-half, but they did not disappear entirely. There are two ways to consider the change in $\mathrm{CON}$ effects. Either they, themselves, were reduced between $\mathrm{P}_{1}$ and $\mathrm{P}_{2}$, releasing focus-tree agr for the more abundant species, or they did not change but were countered by positive effects on agr during recovery after the perturbation. A simple working model might be that $\mathrm{CON}$ effects reduced the growth of focus trees in $\mathrm{P}_{1}$, then during the perturbation (first part of $\mathrm{P}_{2}$ ) they were reduced further by eventinduced (water) stress, and later recovered (second part of $\mathrm{P}_{2}$ ) when both $\mathrm{CON}$ effects were mitigated and better light conditions in the understory enabled them to compensate for the negative stress. By observation alone, it is difficult to establish the relative importance of the direct response, the effect on tree competition, and their interaction. The drought event caused the large (adult) trees to relax their competitive influence, and the hiatus in their growth created better conditions for the smaller trees, especially their own juveniles, to recover. The processes can be viewed as overlapping, with changing emphasis from the perturbation start through to the end of recovery: an interplay of negative and positive effects by the large trees on the agr of small ones.

The mechanism of conspecific effects in $\mathrm{P}_{1}$ remains unresolved. Stoll and Newbery (2005) suggested that it might be competition for nutrients mediated by speciesspecific mycorrhizas. However, testing for differences in phosphorus and nitrogen concentrations in leaves of focus trees with different neighborhoods, albeit later in $\mathrm{P}_{2 \mathrm{~b}}$, failed to show differences (Zurbriggen 2008).

TABLE 3. Predicted absolute growth rates (agr, back-transformed and annualized) at mean basal area in 1986 (ba 1986$)$ and mean

HET evaluated at mean CON and CON-1 (decreasing mean CON by 1 unit on log scale).

\begin{tabular}{|c|c|c|c|c|c|c|c|c|c|c|c|}
\hline \multirow[b]{3}{*}{ Species } & \multirow{3}{*}{$\begin{array}{l}\text { Mean } \\
\text { ba }_{1986}\end{array}$} & \multicolumn{5}{|c|}{$P_{1}(1986-1996)$} & \multicolumn{5}{|c|}{$\mathrm{P}_{2}(1996-2007)$} \\
\hline & & \multicolumn{2}{|c|}{$\operatorname{agr}\left(\mathrm{cm}^{2} / \mathrm{yr}\right)$} & \multicolumn{2}{|c|}{ Change $\left(\mathrm{cm}^{2} / \mathrm{yr}\right)$} & \multirow{2}{*}{$\begin{array}{c}\text { Effect } \\
\text { size }\end{array}$} & \multicolumn{2}{|c|}{$\operatorname{agr}\left(\mathrm{cm}^{2} / \mathrm{yr}\right)$} & \multicolumn{2}{|c|}{ Change $\left(\mathrm{cm}^{2} / \mathrm{yr}\right)$} & \multirow{2}{*}{$\begin{array}{c}\text { Effect } \\
\text { size }\end{array}$} \\
\hline & & $\mathrm{CON}$ & $\mathrm{CON}-1$ & Abs. & Rel. & & $\mathrm{CON}$ & CON-1 & Abs. & Rel. & \\
\hline Barringtonia lanceolata & 78.3 & 0.61 & 0.64 & -0.04 & -0.06 & -0.02 & 0.60 & 0.64 & -0.04 & -0.07 & -0.02 \\
\hline Lithocarpus nieuwenhuisii & 64.1 & 1.69 & 1.75 & -0.06 & -0.04 & -0.01 & 2.13 & 2.73 & -0.61 & -0.29 & -0.20 \\
\hline Parashorea malaanonan & 47.5 & 1.12 & 1.28 & -0.16 & -0.15 & -0.11 & 1.38 & 1.19 & 0.19 & 0.14 & 0.03 \\
\hline Pentace laxiflora & 58.7 & 2.30 & 2.83 & -0.53 & -0.23 & -0.06 & 1.99 & 2.11 & -0.13 & -0.07 & -0.03 \\
\hline Shorea johorensis & 50.6 & 4.30 & 6.13 & -1.84 & -0.43 & -0.40 & 4.15 & 4.70 & -0.55 & -0.13 & -0.12 \\
\hline Shorea parvifolia & 76.4 & 12.60 & 14.28 & -1.68 & -0.13 & -0.17 & 11.81 & 13.48 & -1.67 & -0.14 & -0.16 \\
\hline Shorea pilosa & 43.9 & 2.21 & 2.90 & -0.68 & -0.31 & -0.25 & 2.38 & 2.88 & -0.50 & -0.21 & -0.30 \\
\hline Neoscortechinia philippinensis & 135.5 & 1.13 & 0.98 & 0.15 & 0.13 & 0.16 & 1.14 & 1.22 & -0.08 & -0.07 & -0.05 \\
\hline Shorea pauciflora & 41.1 & 1.11 & 1.40 & -0.28 & -0.25 & -0.20 & 1.30 & 1.49 & -0.19 & -0.15 & -0.12 \\
\hline Dipterocarpus kerrii & 30.8 & 1.03 & 1.13 & -0.10 & -0.10 & -0.11 & 0.63 & 0.56 & 0.08 & 0.12 & 0.04 \\
\hline Drypetes longifolia & 47.4 & 0.43 & 0.37 & 0.06 & 0.14 & 0.12 & 0.42 & 0.34 & 0.08 & 0.19 & 0.23 \\
\hline Lithocarpus gracilis & 48.1 & 7.39 & 7.86 & -0.48 & -0.06 & -0.04 & 2.84 & 3.22 & -0.38 & -0.14 & -0.22 \\
\hline Lithocarpus leptogyne & 50.9 & 3.91 & 4.12 & -0.20 & -0.05 & -0.01 & 3.45 & 3.06 & 0.39 & 0.11 & 0.03 \\
\hline Microcos reticulata & 77.8 & 2.22 & 1.81 & 0.41 & 0.18 & 0.28 & 4.70 & 4.90 & -0.20 & -0.04 & -0.02 \\
\hline Ochanostachys amentacea & 45.0 & 0.89 & 0.88 & 0.01 & 0.01 & $<0.01$ & 1.22 & 1.33 & -0.11 & -0.09 & -0.01 \\
\hline Scorodocarpus borneensis & 73.9 & 1.70 & 2.00 & -0.29 & -0.17 & -0.12 & 2.81 & 2.64 & 0.17 & 0.06 & 0.06 \\
\hline Syzygium lineata & 68.5 & 1.47 & 1.69 & -0.23 & -0.15 & -0.17 & 0.81 & 0.89 & -0.09 & -0.11 & -0.14 \\
\hline Syzygium tawaense & 51.0 & 0.73 & 0.64 & 0.09 & 0.12 & 0.08 & 1.11 & 0.98 & 0.14 & 0.12 & 0.09 \\
\hline
\end{tabular}

Note: Absolute (abs.) and relative (rel.) changes in predicted agr are given together with effect sizes (i.e., squared partial correlation coefficients) of regression models (including bigger neighbors only) at best-fitting radii in $\mathrm{P}_{1}$ (Appendix E: Table E1) and $\mathrm{P}_{2}$ (Table E2). 
Possibly, mycorrhizal linkages were indeed operating in $\mathrm{P}_{1}$, their efficacy reduced by the ENSO in $\mathrm{P}_{2 \mathrm{a}}$, followed by slow recovery into $\mathrm{P}_{2 \mathrm{~b}}$. An alternative hypothesis involves changes in spatiotemporal patterns of light levels below different species' crowns between periods.

The dynamics at Danum are highly responsive to the ENSO perturbation, particularly for growth and recruitment, and not so much for mortality (Newbery and Lingenfelder 2004, 2009). Focusing on small trees (12.5$50 \mathrm{~cm}$ gbh, partially enumerated in 1999 soon after the drought), we found very different growth responses between species, ranging from monotonic decreases and increases through to distinctly oscillating behaviors (Newbery et al. 2011). Based on the present results, we contend that part of this complex spectrum of population dynamics is probably a result also of relaxed conspecific effects. Several common understory species are drought tolerant (Gibbons and Newbery 2003, Newbery and Lingenfelder 2004) and their distributions are strongly associated with plot topography (Newbery et al. 1996, Newbery and Lingenfelder 2009). These species make up a large component of the small stems, and there are indications that they have a "nurse" effect on the agr of juveniles of the overstory species (the facilitation model of Newbery et al. 1999). These together may be the driving processes behind the various oscillatory responses to perturbation (Newbery et al. 2011).

\section{Relaxation mechanism and change}

We have no detailed phenological records before and during the 1998 ENSO. Nevertheless, a plausible mechanism explaining why some species lost their $\mathrm{CON}$ effect, and others retained it, is that different species' large trees lost more or fewer leaves and twigs from the drought. Given that many species are clustered in the overstory, and that their juveniles growing near them are a result of limited seed dispersal (Stoll and Newbery 2005), then the mechanism becomes local and even more species-specific. This would mean that a species sensitive to the ENSO drought as an adult, and that had strong conspecific effects on juveniles in the wet periods, would benefit from the perturbation. The evolutionary cost of poor dispersal, which led to the potentially strong CON effects, might be balanced by the benefits of relaxed competition (i.e., a lessening of abundance dependence). If ontological conformity applies, i.e., juveniles in the understory are also as sensitive to drought as their adults (or more so in the case of the dipterocarps; see Whitmore 1984), then these juveniles also would benefit from the facilitation of the true understory species. In such a scenario, species that retained their $\mathrm{CON}$ effects would be those less affected by drought.

Leaf and small-branch shedding is known to be an adaptation that increases the probability of large-tree survival during short, intensive dry periods (by forestalling embolism development, and thus main-branch or whole-tree death); for data on Danum, see Walsh and Newbery (1999). It may also have the secondary effect of promoting its own population in the form of enhanced growth of its juveniles. Overstory species behaving in this manner would be expected to increase in abundance if ENSO events became more frequent and favored their regeneration. Species that retained $\mathrm{CON}$ effects during perturbations would also be expected to show a sustained abundance and density dependence and, therefore, lowered population densities. Perturbations would then reduce species diversity (at least for the overstory species), not only by selecting those species better adapted to the site and its climate, but also by leading different species to become more or less abundant depending on the degree of mitigation of their conspecific effects. On the one hand, this might account for the apparently idiosyncratic pattern of species' responses, and on the other it could indicate how each species reaches a dynamic equilibrium within its population by regulating adult-juvenile replacement potentials.

Relaxation of the CON effect is likely to have been more intensive within the shorter period between April 1998 and perhaps the end of 1999 (Newbery and Lingenfelder 2004) than was revealed for agr over the whole $\mathrm{P}_{2}$ of 11 years. Although the forest between 2001 and 2007 returned to a dynamics quite similar to $P_{1}$ (D. M. Newbery and C. E. Risdale, unpublished data), there was no return to strong negative $\mathrm{CON}$ effects. The relationship between $\mathrm{CON}$ effects on agr vs. $\ln (\mathrm{BA})$ remained weak (Appendix F: Fig. F1b). To explain this unexpected result, we suggest that while relaxation occurred mainly in $\mathrm{P}_{2 \mathrm{a}}$ for the ENSO-related reasons already suggested, in $\mathrm{P}_{2 b}$ it persisted due to a combination of lagged ENSO effects and continued thinning of small trees in the forest as plot BA rose. This was further evidenced by the decrease in numbers of focus trees of our 18 overstory species that were used in the model fitting: 762 for $\mathrm{P}_{1}, 636$ for $\mathrm{P}_{2} ; 747$ for $\mathrm{P}_{2 \mathrm{a}}, 632$ for $\mathrm{P}_{2 b}$ (see the corollary in Appendix B). One reason for these successive declines in numbers is that several trees, especially of Shorea and Lithocarpus species, advanced out of the small-tree size class. This advancement rate was near constant over $\mathrm{P}_{1}, \mathrm{P}_{2 \mathrm{a}}$, and $\mathrm{P}_{2 \mathrm{~b}}$ (D. $\mathrm{M}$. Newbery, unpublished data).

\section{Longer-term processes}

A further consideration in the loss of $\mathrm{CON}$ effect is that the forest continues to grow toward its maximum basal area, being in a late stage in succession after recovering from a likely major disturbance in the $1870 \mathrm{~s}$ (Newbery et al. 1992). Over the periods $\mathrm{P}_{1}$ and $\mathrm{P}_{2}$, total BA increased and density decreased as the forest continued to thin, with its survivors becoming slightly larger $\left(\mathrm{BA}_{1986}=30.71 \mathrm{~m}^{2} /\right.$ ha [revised for underestimated large trees in 1986 to $31.28 \mathrm{~m}^{2} / \mathrm{ha}$ ], $\mathrm{BA}_{1996}=33.34$, and $\mathrm{BA}_{2007}=33.82 \mathrm{~m}^{2} / \mathrm{ha}$; corresponding densities 2243, 2158 , and $2085 /$ ha; three years after the drought in $\mathrm{P}_{2}$, a 
temporary drop to $\mathrm{BA}_{2001}=32.30 \mathrm{~m}^{2} /$ ha, density $2080 /$ ha; trees $\geq 10 \mathrm{~cm}$ gbh). Plot BA is expected to reach an asymptotic maximum at $\sim 34.5-35 \mathrm{~m}^{2} /$ ha in perhaps 30 50 years time, typical for the region (Fox 1972, 1973). One consequence of this longer-term process is that mean agr values are often higher in $\mathrm{P}_{2}$ than in $\mathrm{P}_{1}$ (Table 3 ), contributing to the suggested compensation that occurred after the 1998 perturbation, and likely also after other preceding events.

The 1998 perturbation appears to have hastened succession because it released CON effects on smaller trees (particularly the dominant overstory ones with largest BA), and again the forest will likely be speciespoorer after such species' selection. Important to note, however, is that $\mathrm{P}_{1}$ started just three years after an earlier ENSO drought perturbation in 1982-1983 (Beaman et al. 1985); therefore, to some extent, $P_{1}$ is not completely perturbation-free. Nevertheless, from the more detailed analysis on small-tree rgr over time (1996-1999-2001), any carry-over effects by 1986 were likely to have been small (Newbery et al. 2011). The dynamics results, and the small shifts in mean focus-tree sizes between periods, further suggest that the change in population composition between $\mathrm{P}_{1}$ and $\mathrm{P}_{2}$ was not indicative of a wave of recruitment resulting from intensive recent regeneration (e.g., due to a masting event), in which case mean focus-tree size would have decreased as more smaller trees moved into $\mathrm{P}_{2}$.

\section{Link between abundance and density dependence}

Change in composition of the focus tree samples between periods appears to have had little effect on the changes in CON effects between $\mathrm{P}_{1}$ and $\mathrm{P}_{2}$, although both were weakly correlated with mortality in $\mathrm{P}_{1}$. This latter result was amplified in the analysis of plot dynamics variables, where the relationship between CON effect and species BA was only markedly influenced by mortality in $\mathrm{P}_{1}$. If $\mathrm{CON}$ effects were mainly working through competition, then increasingly negative values might have resulted in a higher probability of focal-tree death, and thus contributed to the correlation with mortality. Taking this reasoning further, because only trees surviving to the ends of periods were used to derive growth rates, it is also possible that some of those that did not survive succumbed to CON effects earlier in the period, partly explaining their mortalities.

This link between mortality and BA suggests that density dependence was happening because of abundance-dependent CON effects. That the correlation was much weaker in $\mathrm{P}_{2}$ is consistent, too, with the notion that $\mathrm{CON}$ effects were reduced and density dependence was mitigated. The possible causal connection between CON effects on agr in $P_{1}$ and survival into $P_{2}$ is difficult to determine though, largely because the perturbation was associated with reduced agr in $\mathrm{P}_{2}$ (at least in the first part of the period before recovery occurred) and the two main factors were confounded. Trees with slower growth rates in $\mathrm{P}_{1}$ tended to have lower survival in the subsequent period 1996-2001 (Lingenfelder and Newbery 2009), but this slowed growth could have been for other reasons besides $\mathrm{CON}$ effects. If the more indirect CON effects on agr can be supposed to translate into longer-term changes in mortality, whereas the more direct ENSO stress-related effects on agr have most consequences for longer-term recruitment, then together they determine, in a complementary way, a large portion of the population changes recorded for the individual species.

There is some tentative indication of density dependence (at least indirectly) operating at the community level (Connell et al. 1984, Hubbell et al. 2001). At lower basal areas, a few species in $\mathrm{P}_{1}$ actually have positive $\mathrm{CON}$ effects, suggesting that the presence of neighbors improved their growth, contrasting strongly with the more negative effects at higher basal areas (Fig. 2a). This effect remained in $\mathrm{P}_{2}$ for only one of the two species outside the confidence bands. However, none of the species in the present analyses is rare in the plots. New analyses are in preparation to test whether this growth response translates into increased survival, as a demonstration of how less common species may be having a higher probability of remaining in the forest than more common ones. At the community level, for the 18 overstory species, it is nevertheless remarkable that mean CON effect was so close to zero (Table 3), perhaps indicating compensatory processes operating around a dynamic equilibrium that moves along a stabilizing successional trajectory.

\section{Conspecific-effect "by default" or real?}

Determining whether CON effects were real is not straightforward. Randomization of identities cannot fully remove a conspecific component of the neighborhood because, in reallocating tree names to neighbors (not focus trees), it is possible that a tree receives the same name again by chance. The smaller the sample of trees in the size class and the lower the species richness, then the more likely that this same-name replacement will occur. It would make little ecological sense to randomize names of all trees across all sizes of individuals. Among the small trees, this renaming is not so important because, although they are very numerous, each has a small basal area and hence low $\ln \Sigma\left(\mathrm{ba}_{\mathrm{CON}}\right)$ influence. However, the opposite is the case for large trees in the overstory. The very biggest trees have substantial individual basal areas and, hence, very high $\ln \Sigma\left(\mathrm{ba}_{\mathrm{CON}}\right)$ influence, and they are composed of just a few species.

Thus part, or even all, of the so-called CON effect may be "by default," that is, simply a consequence of being clustered, with any focus tree tending to have most of its big neighbors belonging to the same species. This raises a wider and more fundamental problem as to what extent CON effect is "real," in the sense of a mechanism that is biologically and ecologically functional for the 
species alone, and not an artifact of spatial aggregation. Spatially explicit simulations that attempt to recover CON effects may cast more light on this problem, and these are currently in progress. At first interpretation, the randomizations lacking a CON effect on agr vs. $\ln (\mathrm{BA})$ relationship might give credence to real $\mathrm{CON}$ effects increasing with increasing BA in the data. However, randomization of locations largely takes many, but not all, of those same-named large trees out of the neighborhood, and reallocation of names leaves a weaker relationship than would be expected on frequent name reinstatement.

\section{Role of noise in density-dependence realization}

On the decadal time scale, the dynamics of the forest at Danum are not constant because of the ENSO perturbations, and these come on top of a longer-term successional trend. Even so, dynamics appear to be stable overall due to various feedback processes. This situation is represented in theories of nonequilibrium community dynamics (e.g., Huston 1979, DeAngelis and Waterhouse 1987), where perturbations cause small "setbacks" in forest development. It is within these short periods of disruption and disordering that many complex tree-environment and tree-tree interactions are temporarily destabilized. Most indications from Danum suggest that the forest (as of recent times) is both resistant (Newbery and Lingenfelder 2004, 2009) and resilient (Lingenfelder and Newbery 2009, Newbery et al. 2011) to drought perturbation.

On a longer-term perspective, the ENSO perturbations are an example of colored environmental noise (Vasseur and Yodzis 2004), as discussed more fully for Danum by Newbery and Lingenfelder (2009) and Newbery et al. (2011). Such external stochastic processes are increasingly recognized as potential major determinants of complex community dynamics (May 2001). They may help to explain different rates of change, conditions for community stability, and even different levels of species diversity and productivity (Halley 1996, Halley and Inchausti 2004). Hastings (2010) has viewed these periods of disorder and readjustment as displaying "transient dynamics." What happens within and after each of these stochastic perturbations, as forest succession also continues in many cases, could be highly timedependent, i.e., contingent on structural state, species composition, and past perturbation history (Tokeshi 1999). Here, using empirical field measurements, we suggest that perturbations can not only alter different species' growth rates in response to the temporary stress imposed, but they can also significantly alter tree neighborhood interactions. By mitigating conspecific abundance-dependent competition, the overstory species have the opportunity to recruit faster and their juveniles later contribute proportionally more trees to the adult population. After perturbations have passed, other processes remaining equal, the forest returns to its prior state of renewed abundance-dependence and further opportunities are lost until the next perturbation happens. The long-term consequences may essentially depend on inherent nonlinearities. Our means to measure these are severely limited by the overall complexity of the forest, itself changing with time.

\section{ACKNOWLEDGMENTS}

We thank the two anonymous reviewers for valuable comments, M. J. Still, D. Kennedy, M. Lingenfelder, and K. F. Poltz for their assistance with the 1986, 1996, 2001, and 2007 enumerations in the field, and E. J. F. Campbell, L. Madani, and C. E. Ridsdale (Sandakan and Leiden Herbaria) for taxonomic inputs. R. C. Ong kindly provided the connection to the Sabah Forest Department. Permission to conduct research in the Conservation Area was given by the Danum Valley Management Committee (Kota Kinabalu) and the Economic Planning Unit of the Prime Minister's Office (Kuala Lumpur). Financial support to D. M. Newbery by the Swiss National Science Foundation (31003A-110250) is acknowledged.

\section{Literature Cited}

Ahumada, J. A., S. P. Hubbell, R. Condit, and R. B. Foster. 2004. Long-term tree survival in a neotropical forest: the influence of local biotic effect. Pages 408-432 in E. C. Losos and E. G. Leigh, editors. Tropical forest diversity and dynamism. University of Chicago Press, Chicago, Illinois, USA.

Ashton, P. S. 1998. Niche specificity among tropical trees: a question of scales. Pages 491-514 in D. M. Newbery, H. H. T. Prins, and N. D. Brown, editors. Dynamics of tropical communities. Blackwell Sciences, Oxford, UK.

Ashton, P. S., and P. Hall. 1992. Comparisons of structure among mixed dipterocarp forests of north-western Borneo. Journal of Ecology 80:459-481.

Bagchi, R., et al. 2011. Spatial patterns reveal negative density dependence and habitat associations in tropical trees. Ecology 92:1723-1729.

Beaman, R. S., J. H. Beaman, C. W. Marsh, and P. V. Woods. 1985. Drought and forest fires in Sabah in 1983. Sabah Society Journal 8:10-30.

Biging, G. S., and M. Dobbertin. 1992. A comparison of distance-dependent competition measures for height and basal area growth of individual conifer trees. Forest Science 38:695-720.

Blundell, A. G., and D. R. Peart. 2004. Density-dependent population dynamics of a dominant rain forest canopy tree. Ecology 85:704-715.

Canham, C. D., P. T. LePage, and K. D. Coates. 2004. A neighborhood analysis of canopy tree competition: effects of shading versus crowding. Canadian Journal of Forest Research 34:778-787.

Canham, C. D., M. J. Papaik, M. Uriate, W. H. McWilliams, J. C. Jenkins, and M. J. Twery. 2006. Neighborhood analyses of canopy tree competition along environmental gradients in New England forests. Ecological Applications 16:540-554.

Carson, W. P., J. T. Anderson, E. G. Leigh, and S. A. Schnitzer. 2008. Challenges associated with testing and falsifying the Janzen-Connell hypothesis: a review and critique. Pages 211-241 in W. P. Carson and S. A. Schnitzer, editors. Tropical forest community ecology. Wiley-Blackwell, Oxford, UK.

Clark, D. A., and D. B. Clark. 1992. Life-history diversity of canopy and emergent trees in a Neotropical rain forest. Ecological Monographs 62:315-344.

Cohen, J. 1988. Statistical power analysis for the behavioral sciences. Second edition. L. Erlbaum Associates, Mahwah, New Jersey, USA. 
Comita, L. S., and S. P. Hubbell. 2009. Local neighborhood and species' shade tolerance influence survival in a diverse seedling bank. Ecology 90:328-334.

Comita, L. S., H. C. Muller-Landau, S. Aguilar, and S. P. Hubbell. 2010. Asymmetric density dependence shapes species abundances in a tropical tree community. Science 329:330-332.

Condit, R., et al. 2000. Spatial patterns in the distribution of tropical tree species. Science 288:1414-1418.

Condit, R., S. P. Hubbell, and R. B. Foster. 1994. Density dependence in two understory tree species in a Neotropical forest. Ecology 75:671-680.

Connell, J. H., J. G. Tracey, and L. J. Webb. 1984. Compensatory recruitment, growth, and mortality as factors maintaining rain forest tree diversity. Ecological Monographs 54:141-164.

DeAngelis, D. L., and J. C. Waterhouse. 1987. Equilibrium and non-equilibrium concepts in ecological models. Ecological Monographs 57:1-21.

Feeley, K. J., S. J. Davies, R. Perez, S. P. Hubbell, and R. B. Foster. 2011. Directional changes in the species composition of a tropical forest. Ecology 92:871-882.

Fox, J. E. D. 1972. The natural vegetation of Sabah and natural regeneration of dipterocarp forests. Dissertation. University of Wales, Bangor, Wales.

Fox, J. E. D. 1973. A handbook to Kabili-Sepilok Forest Reserve. Sabah Forest Record Number 9. Borneo Literature Bureau for Sabah Forest Department, Sandakan, Borneo.

Gibbons, J. M., and D. M. Newbery. 2003. Drought avoidance and the effect of local topography on trees in the understorey of Bornean lowland rain forest. Plant Ecology 164:1-18.

Gilbert, G. S., K. E. Harms, D. N. Hamill, and S. P. Hubbell. 2001. Effects of seedling size, El Niño drought, seedling density, and distance to nearest conspecific adult on 6-year survival of Ocotea whitei seedlings in Panama. Oecologia 127: 509-516.

Halley, J. M. 1996. Ecology, evolution and 1/f-noise. Trends in Ecology and Evolution 11:33-37.

Halley, J. M., and P. Inchausti. 2004. The increasing importance of $1 / \mathrm{f}$-noises as models of ecological variability. Fluctuation and Noise Letters 4:R1-R26.

Harms, K. E., S. J. Wright, O. Calderon, A. Hernandez, and E. A. Herre. 2000. Pervasive density-dependent recruitment enhances seedling diversity in a tropical forest. Nature 404: 493-495.

Hastings, A. 2010. Timescales, dynamics, and ecological understanding. Ecology 91:3471-3480.

Hubbell, S. P., J. A. Ahumada, R. Condit, and R. B. Foster. 2001. Local neighborhood effects on long-term survival of individual trees in a neotropical forest. Ecological Research 16:859-875.

Hubbell, S. P., R. Condit, and R. B. Foster. 1990. Presence and absence of density dependence in a neotropical tree community. Philosophical Transactions of the Royal Society B 330:269-281.

Huston, M. 1979. General hypothesis of species diversity. American Naturalist 113:81-101.

Kohyama, T. 1992. Density-size dynamics of trees simulated by a one-sided competition multi-species model of rain forest stands. Annals of Botany 70:451-460.

Lingenfelder, M., and D. M. Newbery. 2009. On the detection of dynamic responses in a drought-perturbed tropical rainforest in Borneo. Plant Ecology 201:267-290.

Mangan, S. A., S. A. Schnitzer, E. A. Herre, K. M. L. Mack, M. C. Valencia, E. I. Sanchez, and J. D. Bever. 2010. Negative plant-soil feedback predicts tree-species relative abundance in a tropical forest. Nature 466:752-755.

Manokaran, N., and K. M. Kochummen. 1987. Recruitment, growth and mortality of tree species in a lowland dipterocarp forest in peninsular Malaysia. Journal of Tropical Ecology 3: 315-330.
May, R. M. 2001. Stability and complexity in model ecosystems. Landmarks in biology. Second edition. Princeton University Press, Princeton, New Jersey, USA.

Metz, M. R., W. P. Sousa, and R. Valencia. 2010. Widespread density-dependent seedling mortality promotes species coexistence in a highly diverse Amazonian rain forest. Ecology 91: 3675-3685.

Moravie, M.-A., M. Durand, and F. Houllier. 1999. Ecological meaning and predictive ability of social status, vigour and competition indices in a tropical rain forest (India). Forest Ecology and Management 117:221-240.

Newbery, D. M., E. J. F. Campbell, Y. F. Lee, C. E. Ridsdale, and M. J. Still. 1992. Primary lowland dipterocarp forest at Danum Valley, Sabah, Malaysia: structure, relative abundance and family composition. Philosophical Transactions of the Royal Society B 335:341-356.

Newbery, D. M., E. J. F. Campbell, J. Proctor, and M. J. Still. 1996. Primary lowland dipterocarp forest at Danum Valley, Sabah, Malaysia. Species composition and patterns in the understorey. Vegetatio 122:193-220.

Newbery, D. M., D. N. Kennedy, G. H. Petol, L. Madani, and C. E. Ridsdale. 1999. Primary forest dynamics in lowland dipterocarp forest at Danum Valley, Sabah, Malaysia, and the role of the understorey. Philosophical Transactions of the Royal Society B 354:1763-1782.

Newbery, D. M., and M. Lingenfelder. 2004. Resistance of a lowland rain forest to increasing drought intensity in Sabah, Borneo. Journal of Tropical Ecology 20:613-624.

Newbery, D. M., and M. Lingenfelder. 2009. Plurality of tree species responses to drought perturbation in Bornean tropical rain forest. Plant Ecology 201:147-167.

Newbery, D. M., M. Lingenfelder, K. F. Poltz, R. C. Ong, and C. E. Ridsdale. 2011. Growth responses of understorey trees to drought perturbation in tropical rainforest in Borneo. Forest Ecology and Management 262:2095-2107.

R Development Core Team. 2012. R: A language and environment for statistical computing. R Foundation for Statistical Computing, Vienna, Austria.

Seidler, T. G., and J. B. Plotkin. 2006. Seed dispersal and spatial pattern in tropical trees. PLoS Biology 4:2132-2137.

Sorrensen-Cothern, K. A., E. D. Ford, and D. G. Sprugel. 1993. A model of competition incorporating plasticity through modular foliage and crown development. Ecological Monographs 63:277-304.

Stoll, P., and D. M. Newbery. 2005. Evidence of species-specific neighborhood effects in the Dipterocarpaceae of a Bornean rain forest. Ecology 86:3048-3062.

Terborgh, J. 2012. Enemies maintain hyperdiverse tropical forests. American Naturalist 179:303-314.

Tokeshi, M. 1999. Species coexistence. Blackwell Science, Oxford, UK.

Uriarte, M., C. D. Canham, J. Thompson, and J. K. Zimmerman. 2004a. A neighborhood analysis of tree growth and survival in a hurricane-driven tropical forest. Ecological Monographs 74:591-614.

Uriarte, M., R. Condit, C. D. Canham, and S. P. Hubbell. 2004b. A spatially explicit model of sapling growth in a tropical forest: does the identity of neighbours matter? Journal of Ecology 92:348-360.

Uriarte, M., S. P. Hubbell, R. John, R. Condit, and C. Canham. 2005. Neighbourhood effects on sapling growth and survival on a neotropical forest and the ecologicalequivalence hypothesis. Pages 89-106 in D. F. R. P. Burslem, M. A. Pinard, and S. Hartley, editors. Biotic interactions in the tropics. Cambridge University Press, Cambridge, UK.

Vanclay, J. K. 2006. Spatially-explicit competition indices and the analysis of mixed-species plantings with the Simile modelling environment. Forest Ecology and Management 233:295-302.

Vasseur, D. A., and P. Yodzis. 2004. The color of environmental noise. Ecology 85:1146-1152. 
Walsh, R. P. D. 1996. Drought frequency changes in Sabah and adjacent parts of northern Borneo since the late nineteenth century and possible implications for tropical rain forest dynamics. Journal of Tropical Ecology 12:385-407.

Walsh, R. P. D., and D. M. Newbery. 1999. The ecoclimatology of Danum, Sabah, in the context of the world's rainforest regions, with particular reference to dry periods and their impact. Philosophical Transactions of the Royal Society B 354:1869-1883.

Warner, R. M. 2012. Applied statistics: from bivariate to multivariate techniques. Second edition. Sage Publications, Washington, D.C., USA.

Webb, C. O., and D. R. Peart. 1999. Seedling density dependence promotes coexistence of Bornean rain forest trees. Ecology Letters 80:2006-2017.

Whitmore, T. C. 1984. Tropical rain forests of the Far East. Second edition. Oxford University Press, Oxford, UK.
Wills, C., and R. Condit. 1999. Similar non-random processes maintain diversity in two tropical rainforests. Proceedings of the Royal Society B 266:1445-1452.

Wills, C., R. Condit, R. B. Foster, and S. P. Hubbell. 1997. Strong density- and diversity-related effects help to maintain tree species diversity in a neotropical forest. Proceedings of the National Academy of Sciences USA 94:1252-1257.

Wright, S. J. 2002. Plant diversity in tropical forests: a review of mechanisms of species coexistence. Oecologia 130:1-14.

Zuidema, P. A., R. J. W. Brienen, H. J. During, and B. Guneralp. 2009. Do persistently fast-growing juveniles contribute disproportionately to population growth? A new analysis tool for matrix models and its application to rainforest trees. American Naturalist 174:709-719.

Zurbriggen, N. 2008. Influence of conspecific neighbourhood on growth and nutrient status among dipterocarp trees in primary lowland rain forest at Danum, Sabah, Malaysia. Thesis. University of Bern, Bern, Switzerland.

\section{Supplemental Material}

Appendix A

Species used in neighborhood analysis (Ecological Archives E094-262-A1).

Appendix B

Details and results of randomization tests (Ecological Archives E094-262-A2).

\section{Appendix C}

Sensitivity analyses of results (Ecological Archives E094-262-A3).

\section{Appendix D}

Effects of including dead neighbors and correcting for gbh measurement errors (Ecological Archives E094-262-A4).

Appendix E

Estimates of regression models (Ecological Archives E094-262-A5).

\section{Appendix F}

Regression and randomizations for sub-periods $\mathrm{P}_{2 \mathrm{a}}$ and $\mathrm{P}_{2 \mathrm{~b}}$ (Ecological Archives E094-262-A6). 